\title{
The Caps and Floor Limits on Premium Periodic Unit- Linked Insurance with Minimum Guarantee
}

\author{
Putu Febani Wisanta ${ }^{1, *}$ Bona Christanto Siahaan ${ }^{2}$
}

\author{
${ }^{1}$ Universitas Indonesia \\ ${ }^{2}$ Universitas Indonesia \\ *Corresponding author.putu.febani@yahoo.co.id
}

\begin{abstract}
Unit-linked endowment insurance with a minimum guarantee not only provides life protection to customers until the end of the insurance contract period but also provides investment protection, especially stock investments that have high returns and high investment risks, so call options are needed to protect investments. This study discusses premiums' calculation along with the caps and floor limits of premiums on unit-linked endowment insurance products with minimum guarantees using Monte Carlo simulations with stochastic and continuous model and numerical methods. Unit-linked insurance with stock investment and mortality tables in this study shows that in addition to gender, the customer's initial age has a policy, insurance contract, and amount minimum guarantee, the caps and floor limits of the premium are influenced by the proportion of investment from the premium. The interval between the caps and floor limits of the premium is more comprehensive if the premium's investment proportion is small so that the insurance company can use the caps limits of the premium.
\end{abstract}

Keywords: Unit-Linked Endowment Insurance, Minimum Guarantee, Caps and Floor Limits on Premium.

\section{INTRODUCTION}

Unit-Linked is a life insurance product that provides life protection and investment returns [1]. If life insurance provides a minimum guarantee to the policyholder, then the policyholder bears the investment risk. If not, then the policyholder who bears the investment risk. The benefits of unit-links with a minimum guarantee combine the risk of death of customers whose date of uncertain benefit payments and investment risk whose investment performance is uncertain so that it has a random nature of unit-link benefits [2].

Early research that examines unit-linked contracts is carried out by [3], which discussed the equilibrium price of life insurance policies related to equity or equitylinked assets. [4] address the issue of endowment policy pricing where benefits are associated with portfolio effects and the minimum amount guaranteed is given at the stochastic interest rate. [5] present a general framework for setting life insurance contract prices with surrender guarantees. [2] analyzes premiums by considering stochastic interest rates, policy contracts, the proportion of premiums invested in the portfolio, call option prices, and death risk. The problem is the lack of analytical capabilities outside of the Monte Carlo method in calculating unit-linked premiums [2].

This study aims to calculate the upper and lower limits of premiums on unit-linked endowment insurance products with minimum guarantees using Monte Carlo simulations with stochastic and continuous model and numerical methods. This study analyzes how stock investment, length of the contract, the age factor of the insured, and the proportion of investment in the premium affect the value of the caps and floor premiums so that insurance companies have a premium distance in determining premiums to the insured by taking into account the proportion of investment in premiums.

\section{The Unit-Linked Endowment contract with a guarantee}

Value of benefit unit-linked endowment contract with a guarantee at time $t$ stated as follows (1). 


$$
B(t)=\max \{X(t), G\}=G+\max \{X(t)-G, 0\}
$$

The unit-link benefit value is the maximum value between the portfolio value that becomes the basic asset of the investment $X(t)$ and the minimum guarantee value $G$. So, the unit-linked benefit value consists of a minimum guarantee value and a non-negative bonus value. The bonus value represents the reference portfolio's call option value with the minimum guarantee value as the exercise price [2]. Value $\boldsymbol{X}(t)$ is stochastic and depends on the price of the asset of the investment per unit at time $t$.

\section{Caps and Floor Limits for Premium}

According to the method of [6], the number of portfolio stock price comparisons at $t+1$ is proportional to the number of log-normal random variables to analyze call option prices $C_{0}(X(t+1), G)$ for $t=0,1_{x, \ldots} n-1$ follow (2).

$Y(k)=\sum_{i=0}^{k-1} \frac{S(k)}{S(i)}=\sum_{i=0}^{k-1} \alpha_{i}(k) e^{Z_{i}(k)}, \mathrm{k}=1,2,3, \ldots, \mathrm{n}$

Where $\alpha_{i}(k)$ is a non-negative constant and $\left(Z_{0}(k), Z_{1}(k), \ldots, Z_{n-1}(k)\right)$ is a multivariate normally distributed random vector with vector mean $\mu_{i}(k)=E\left[Z_{i}(k)\right]$ and Cov covariance matrix $\operatorname{Cov}\left[Z_{i}(k), Z_{j}(k)\right]=\operatorname{Var}\left[Z_{i}(k)\right]_{s} \rho_{i j}(k) \sigma_{i j}(k) \sigma_{j}(k)$.

For fixed $k$, consider the random variable conditioning as follows (3) and (4).

$$
\begin{gathered}
\Lambda(k)=\sum_{i=1}^{k-1} \gamma_{i}(k) Z_{i}(k) \\
\gamma_{i}(k)=\alpha_{i}(k) e^{\mu_{i}(k)+\frac{1}{2} \sigma_{i}(k)^{2}}
\end{gathered}
$$

The calculation of the floor limit premium begins by entering coefficient of $\beta^{\mathbb{l}}>0$ and $x(k)>0$ in the equation (Hürlimann, 2010) follow (5).

$$
\begin{aligned}
& \sum_{i=1}^{n} \gamma_{i}(k) e^{-\frac{1}{2} r_{i}(k)^{2} \sigma_{i}(k)^{2}+r_{i}(k) \sigma_{i}(k) x(k)} \\
& =\frac{\beta^{l}}{P(0,1)}, k=1,2, \ldots, n
\end{aligned}
$$

Furthermore, using numerical methods to get coefficient of $\beta^{\mathbb{1}}$ and $x(k)$. The next step is to enter the coefficient of $\beta^{\mathbb{l}}$ and $x(k)$ into the equation (Hürlimann, (12010) follow (6)

$$
\begin{aligned}
& \frac{1}{a} \cdot \sum_{k=1}^{n-1} P(0, k)_{k} p_{x}=\frac{\beta^{l}}{P(0,1)} \\
& \cdot\left[\begin{array}{l}
\left.\sum_{k=1}^{n-1} P(0, k)_{k-1} p_{x} q_{x+k-1} \Phi(x(k))\right] \\
+P(0, n)_{n-1} p_{x} \Phi(x(n))
\end{array}\right] \\
& +\sum_{k=1}^{n-1}\left[\sum_{i=0}^{k-1} p_{x} q_{x+k-1} \cdot\right. \\
& +{ }_{n-1}^{k-1} p_{x} \cdot \sum_{i=0}^{n-1} P(0, i) \Phi\left(r_{i}(k) \sigma_{i}(k)-x(k)\right)
\end{aligned}
$$

Using numerical methods to get coefficient $a \mathrm{n}$ approximation which proportion of investment in the premium so that it approaches the $a$ value that has been determined at the beginning.

The last step is to enter the final value $\beta^{l}$ in the equation [2] follow (7).

$$
P^{l}=\frac{P(0,1)}{\beta^{l}} \cdot \frac{G}{a}
$$

to get floor premiums unit-linked endowment insurance.

The same way to calculate the caps limit premium, but what distinguishes the lower limit premium is the (3) value $n_{1}(k)=1$. So after getting the final value $\beta^{u}$, the equation caps premiums unit-linked endowment insurance is follow (8).

$$
P^{u}=\frac{P(0,1)}{\beta^{u}} \cdot \frac{G}{a}
$$

\section{METHODS}

In calculating premiums, the factors are proportion, minimum guarantee value, length of the contract, call option, and mortality rates (age and gender). This research begins by determining the unit link product, assumptions, and limitations in calculations. Unit link (5i)nsurance product from $\mathrm{PT} \mathrm{ABC}$, a life insurance company, is a unit link product with a stock investment strategy. The data sample used is secondary data, the daily closing price data for one year in the period 1 May 
2017, until 30 April 2018, which consists of 76 stocks. The limitation in this study is to use a minimum guarantee fixed value of $\mathrm{Rp} 125$ million, benefit payments made at the end of the year of death, using the age of the insured from 20 years to 50 years, the length of the insurance contract is 5, 10 and 15 years and periodic annual premiums. Mortality rates are calculated using the Indonesian Death Table (TMI 2011) issued by the Indonesian Life Insurance Association (AAJI) for every male and female. The upper and lower limits' premium values are calculated using numerical and Monte Carlo methods, using R software.

\section{RESULTS AND DISCUSSION}

\section{Floor Premium}

Six larger stocks in portfolio stock used as an investment instrument in unit-linked insurance are the BBCA $11.72 \%$, BBRI $8.29 \%$, HMSP $7.66 \%$, and TLKM $7.54 \%$, ASCII $6.54 \%$, and BMRI $6.48 \%$.

In calculating the floor limit premium unit-linked insurance with a minimum guarantee that uses numerical and Monte Carlo methods, the author uses an error value of 0.005 . After calculating with numerical methods in equations (5), (6), and (7), get the results of the floor limit unit link insurance premium with a minimum guarantee.

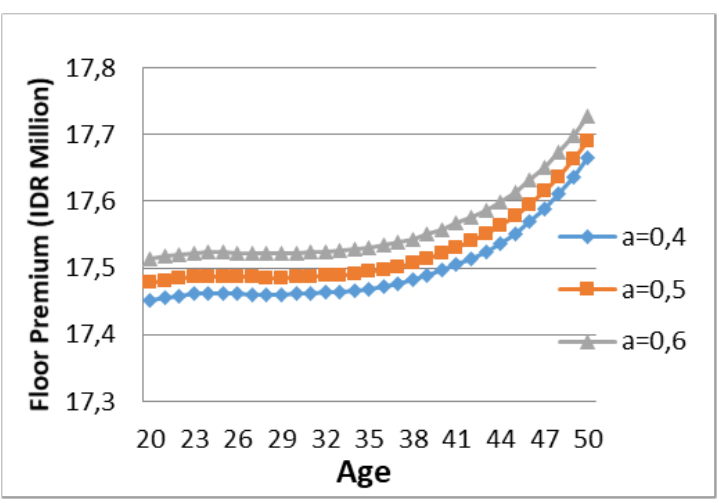

Figure 1. Graph of the floor limit of premiums for men and the 5-year period.

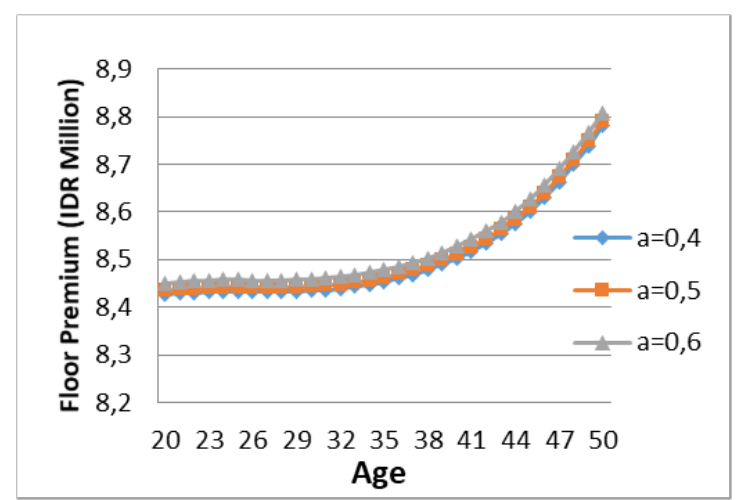

Figure 2 Graph of the floor limit of premiums for men and the 10 -year period.

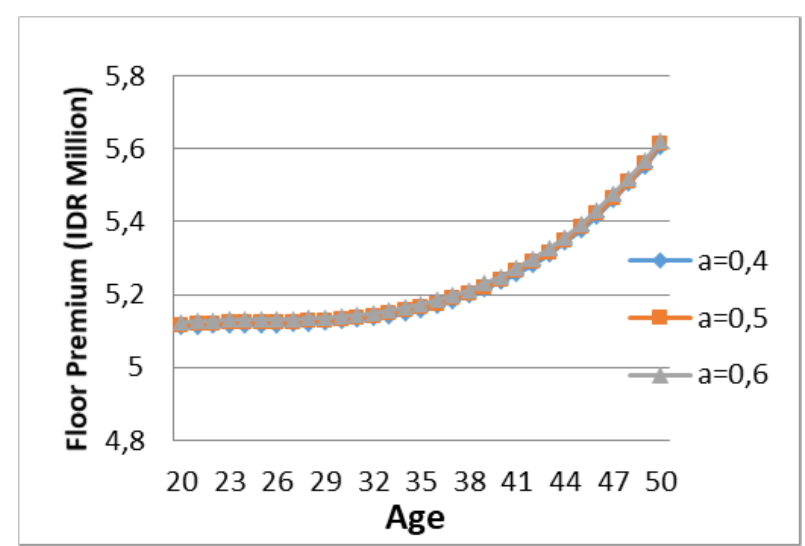

Figure 3. Graph of the floor limit of premiums for men and the 15 -year period.

From the graph above fig. 1., fig. 2., and fig. 3., besides being influenced by the gender of the insured, the initial age of the insured when entering the insurance policy, the duration of the contract, and the amount of the minimum guarantee, the premium floor limit is also influenced by the large proportion of investment from premium (a). The greater the proportion of investment from premiums (a), the floor the premium value greater. The smaller the proportion of investment from premiums (a), the floor the premium value smaller.

\section{Caps Premium}

The process of calculating the caps limit premium unit-linked insurance with a minimum guarantee is the same as the floor limit. Only what applies to this case uses the $r_{1}(k)=1$ coefficient.

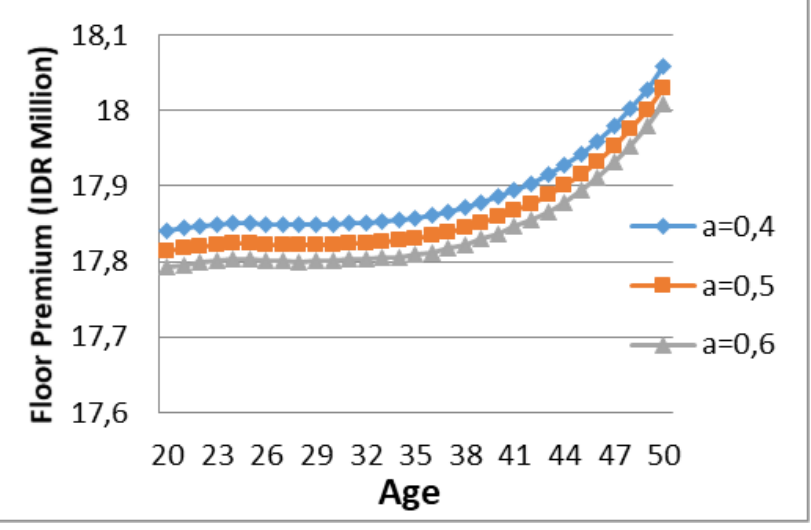

Figure 4. Graph of the caps limit of premiums for men and the 5-year period. 


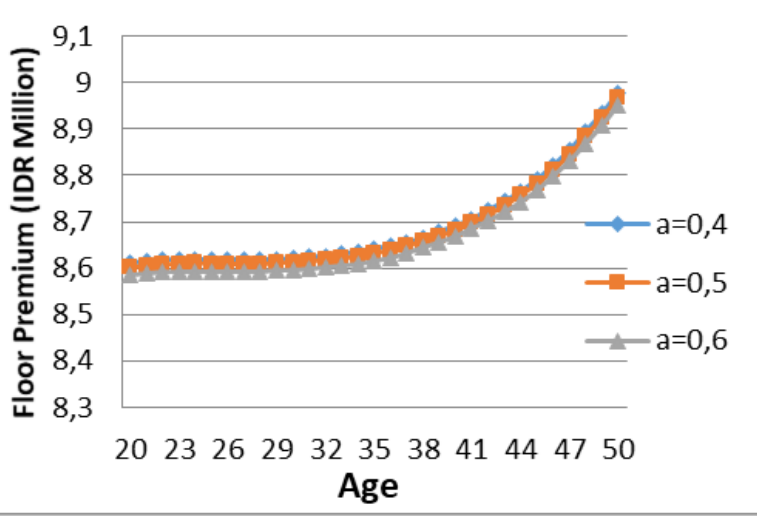

Figure 5. Graph of the caps limit of premiums for men and the 10 -year period.

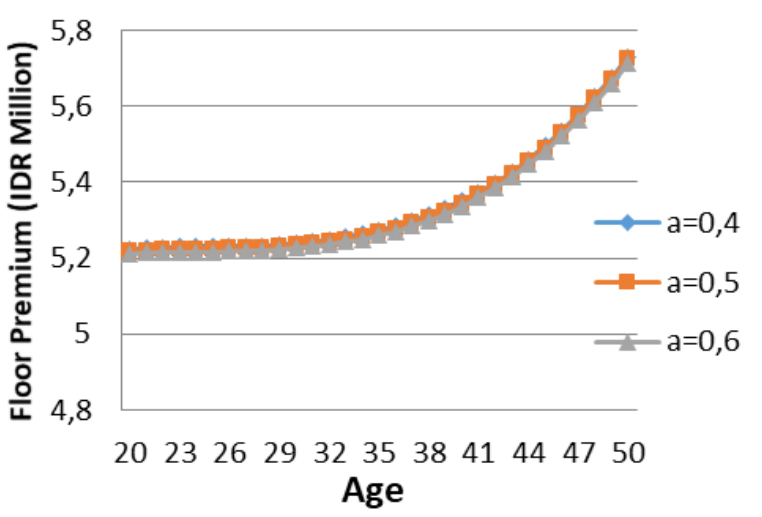

Fugure 6. Graph of the caps limit of premiums for men and the 15-year period.

From the graph above on fig. 4., fig. 5., and fig. 6., same as the floor limit premium value, the premium caps limit is also influenced by the large proportion of investment from premium (a). The difference is the greater the proportion of investment from premiums (a), the caps the premium value smaller. The smaller the proportion of investment from premiums (a), the caps the premium value greater. So the smaller the proportion of investment from premiums, the wider the interval of premium prices. Conversely, the greater the proportion of investment from premiums, the narrower the premium price interval.

\section{CONCLUSIONS}

From the calculation of the caps and floor limit of unit-linked insurance premiums with a minimum guarantee, the authors conclude that the distance of the premium price from the caps limit of the premium to the floor premium limit is influenced by the large proportion of investment from premiums (a). The smaller the proportion of investment from premiums, the wider the interval of premium prices. Conversely, the greater the proportion of investment from premiums, the narrower the premium price interval at PT ABC life insurance company. Besides being influenced by the large proportion of investment from premiums, it is also influenced by age, gender, and contract length.

The difference in premiums influenced by gender is caused by the mortality value of each gender. In the mortality table, men are less likely to live than women at the same age, so male premiums are more expensive. The difference in premiums influenced by age is caused by the mortality value of each age. The mortality table shows that young people can live for the next year greater than old age so that premiums for young people are cheaper. The difference in premiums is influenced by the length of the insurance contract. The longer the insurance contract, the cheaper the premium for the minimum fixed-guarantee value.

Suppose the insured or insurance company wants the investment proportion of the premium to be small. In that case, this means the opportunity for the total investment value exceeds the minimum guarantee at the end of the contract so that the life insurance company can provide caps premiums to the insured for unitlinked insurance products with a minimum guarantee.

\section{REFERENCES}

[1] D. F. Schrager and A. A. J. Pelsser, "Pricing Rate of Return Guarantees in Regular Premium Unit Linked Insurance," Insur. Math. Econ., vol. 35, no. 2 SPEC. ISS., 2004, doi: 10.1016/j.insmatheco.2004.07.003.

[2] W. Hürlimann, "Analytical pricing of the unitlinked endowment with guarantees and periodic premiums," Astin Bull., vol. 40, no. 2, 2010, doi: 10.2143/AST.40.2.2061131.

[3] M. J. Brennan and E. S. Schwartz, "The pricing of equity-linked life insurance policies with an asset value guarantee," J. financ. econ., vol. 3, no. 3, 1976, doi: 10.1016/0304-405X(76)90003-9.

[4] A. R. Bacinello and F. Ortu, "Pricing equity-linked life insurance with endogenous minimum guarantees," Insur. Math. Econ., vol. 12, no. 3, 1993, doi: 10.1016/0167-6687(93)90236-I.

[5] A. R. Bacinello, E. Biffis, and P. Millossovich, "Regression-based algorithms for life insurance contracts with surrender guarantees," Quant. Financ., vol. 10, no. 9, 2010, doi: $10.1080 / 14697680902960242$.

[6] [6]J. Dhaene, M. Denuit, M. J. Goovaerts, R. Kaas, and D. Vyncke, "The concept of comonotonicity in actuarial science and finance: Applications," Insurance: Mathematics and Economics, vol. 31, no. 2. 2002, doi: 10.1016/S0167-6687(02)00135-X. 
[7] 2016. BPS Laporan Statistik Indonesia [Online]. Available: https://www.bps.go.id/

[8] 2017, BPS. Laporan Statistik Indonesia. [Online]. Available: https://www.bps.go.id/

[9] 2014. BI, Laporan Perekonomian Indonesia. [Online]. Available: https://www.bi.go.id/

[10]DJPPR kemenkeu. [Online]. Available: http://www.djppr.kemenkeu.go.id

[11]2016, OJK, Buku Dana Pensiun. [Online]. Available: https://www.ojk.go.id/id/kanal/iknb/data-danstatistik/dana pensiun/Documents/Pages/BukuStatistik-Dana-Pensiun-2016

[12]2017, OJK. Laporan Tahunan Otoritas Jasa Keuangan. [Online]. Available: http: www.ojk.go.id/id/ data-dan-statistik /laporantahunan/Pages

[13]2015, POJK, Peraturan Otoritas Jasa Keuangan. [Online]. Available http://www.ojk.go.id/id/regulasi/ otoritas-jasakeuangan/peraturan-ojk/Pages. 